\title{
E-Cadherin Promoter Hypermethylation in Preneoplastic and Neoplastic Skin Lesions
}

Melissa C. Chiles, M.D., Lingbao Ai, M.D., Chunlai Zuo, M.D., Chun-Yang Fan, M.D., Ph.D., Bruce R. Smoller, M.D.

Department of Pathology (MCC, LA, CL, CYF, BRS) and Dermatology (BRS), University of Arkansas for Medical Sciences, and John L. McClellan Memorial Veterans Administration Hospital, Little Rock, Arkansas (CYF, BRS); and College of Public Health (LA), Sun-Yat Sen University, Guangzhou, People's Republic of China

E-cadherin is a calcium-dependent, intercellular adhesion molecule that is specifically expressed in epithelial tissues and plays an important role in maintaining epithelial stability. E-cadherin is widely regarded as a prognostic marker in many types of human cancers. The inactivation of the $E$-cadherin gene is linked to increased potential for tumor invasiveness and distant metastasis. We previously demonstrated reduced expression of E-cadherin protein immunohistochemically in invasive squamous cell carcinomas of the skin as compared with adjacent normal skin. An epigenetic alteration in association with promoter hypermethylation is one important mechanism of gene silencing. In the present study, we analyze the E-cadherin gene promoter hypermethylation in preneoplastic and neoplastic skin lesions to determine whether epigenetic alteration of the E-cadherin gene also plays an important role in cutaneous squamous carcinogenesis. A total of 33 cases was examined for evidence of E-cadherin promoter hypermethylation, and these consist of nine cases of spongiotic dermatitis as nonneoplastic skin control, nine cases of actinic keratosis, eight cases of squamous cell carcinoma in situ, and seven cases of invasive squamous cell carcinoma. Promoter hypermethylation of the E-cadherin gene was detected in 6 of 7 cases (85\%) of invasive squamous cell carcinoma, 4 of 8 cases (50\%) of squamous cell carcinoma in situ, 4 of

Copyright () 2003 by The United States and Canadian Academy of Pathology, Inc.

VOL. 16, NO. 10, P. 1014, 2003 Printed in the U.S.A.

Date of acceptance: June 20, 2003.

MCC and LA contributed equally to the work presented in this article.

Presented at the 92nd Annual Meeting of the United States and Canadian

Academy of Pathology, March 22-28, 2003, Washington, District of

Columbia.

Address reprint requests to: Bruce R. Smoller, M.D., Director of Dermatopathology, Department of Pathology, University of Arkansas for Medical Sciences, 4301 West Markham, Slot 517, Little Rock, AR 72205; fax: 501603-1479; e-mail: smollerbruce@exchange.uams.edu.

DOI: 10.1097/01.MP.0000089779.35435.9D
9 cases (44\%) of actinic keratosis, and 2 of 9 cases (22\%) of nonneoplastic skin. We conclude that E-cadherin promoter hypermethylation occurs frequently and may represent an important mechanism of $E$-cadherin inactivation in cutaneous preneoplastic and neoplastic lesions. The frequencies of E-cadherin promoter hypermethylation appear to be correlated with more advanced stage of squamous carcinogenesis in skin.

KEY WORDS: Cutaneous squamous cell carcinoma, E-cadherin, Promoter hypermethylation.

Mod Pathol 2003;16(10):1014-1018

E-cadherin is a calcium-dependent cell adhesion molecule, which is expressed primarily on the surface of epithelial cells. E-cadherin plays a major role in cell-cell interactions in epithelium and is critical in maintaining the structure and integrity of the epithelial sheet (1). The E-cadherin gene is localized at $16 q 24.3$ (2), a chromosomal region demonstrating frequent allelic loss in many types of human cancer, including breast and lung carcinomas $(2,3)$. It has also been demonstrated that E-cadherin expression is greatly reduced in many types of human cancer, such as cancer in the breast, prostate, colon, stomach, esophagus, thyroid, head and neck, and bladder, as compared with normal epithelial tissues $(4,5)$. Thus, the E-cadherin gene is widely regarded as a tumor suppressor gene, and inactivation of this gene is critically involved in tumor formation, invasiveness, and metastatic potential (6).

According to Knudson's (7) "two-hit" hypothesis, both alleles of a tumor-suppressor gene have to be inactivated for complete loss of function. Allelic loss of one allele is often associated by gene mutation or other forms of aberrations, such as promoter methylation in the second allele $(8,9)$.

Promoter $\mathrm{CpG}$ island hypermethylation (epigenetic alteration) is one important mechanism for gene inactivation in human cancer (10). The epige- 
netic silencing of the E-cadherin gene has been reported in a wide variety of human tumors including gastric $(11,12)$, prostatic (13), cervical (14), colorectal $(15)$, bladder $(16,17)$, breast $(18)$, esophageal (19), and head and neck squamous cell carcinoma (20-22).

Extensive studies on cutaneous malignancies also establish that E-cadherin protein expression is reduced in both basal cell carcinoma $(23,24)$ and squamous cell carcinoma (25-29) by immunohistochemistry. It appears that loss of E-cadherin protein expression is associated with high mitotic index (29) and increased metastatic potential (25) in cutaneous squamous cell carcinoma. Work in our laboratory and others has also demonstrated that loss of E-cadherin protein expression is associated with poorer tumor differentiation $(27,28)$. Promoter hypermethylation of the E-cadherin gene in cutaneous malignant lesions has not been analyzed previously.

\section{MATERIALS AND METHODS}

\section{Tissue Collection}

A total of 33 cases of nonneoplastic skin, actinic keratosis, and skin cancers were gathered from the paraffin block archives in the Department of Pathology, University of Arkansas for Medical Sciences, in 2002. These cases consisted of eight cases of nonneoplastic skin control, nine cases of actinic keratosis, eight cases of squamous cell carcinoma in situ, and seven cases of invasive squamous cell carcinoma (Table 1).

\section{DNA Extraction and Bisulfite Modification}

DNA samples were collected using the EX-WAX DNA Extraction Kit (Intergen Co., New York, NY) from five deparaffinized $5-\mu \mathrm{m}$-thick tissue sections from each tissue block, followed by bisulfite modification before methylation-specific PCR using CpGenome DNA modification Kit (Intergen Co.).

\section{PCR Amplification and Primers}

Amplification of the promoter region of the E-cadherin gene was carried out in a Touchgene Gradient Thermal Cycler (Techne Inc., Princeton, NJ) in a $50-\mu \mathrm{L}$ PCR reaction mixture containing 2 $\mu \mathrm{L}$ of bisulfite-treated genomic DNA as described previously (30). The primers used for the unmethylated reaction were as follows: 5'-TAA TTT TAG GTT AGA GGG TTA TTG T-3' (sense); and 5'-CAC AAC CAA TCA ACA ACA CA-3' (antisense); the primers used for the methylated reaction were as follows: 5'-TTA GGT TAG AGG GTT ATC GCG T-3' (sense) and 5'-TAA CTA AAA ATT CAC CTA CCG AC-3' (antisense). All primers were purchased from
Operon Technologies Inc. (Alameda, CA). The PCR conditions were as follows: initial denaturation and hot start at $95^{\circ} \mathrm{C}$ for 15 minutes, then 40 cycles consisting of 30 seconds at $95^{\circ} \mathrm{C}, 30$ seconds at $53^{\circ}$ $\mathrm{C}$ (unmethylated reactions) or $57^{\circ} \mathrm{C}$ (methylated reactions), and 1 minute at $72^{\circ} \mathrm{C}$. Positive- and negative-control DNA samples and controls without DNA were used for each set of PCR reactions.

\section{RESULTS}

We used a highly specific and sensitive methylation-specific PCR to analyze the status of promoter methylation of the E-cadherin gene in 33 cases of nonneoplastic skin, actinic keratosis, squamous cell carcinoma in situ, and invasive squamous cell carcinoma using gene specific primer sets as described previously (30). Spongiotic dermatitis was used as the nonneoplastic skin control. The distribution of cases and analysis results are presented in Table 1.

Promoter hypermethylation of the E-cadherin gene was detected in 6 of 7 cases (85\%) of invasive squamous cell carcinoma, 4 of 8 cases $(50 \%)$ of squamous cell carcinoma in situ, 4 of 9 cases (44\%) of actinic keratosis, and 2 of 9 cases (22\%) of non-

Table 1. E-Cadherin Promotor Hypermethylation in Skin Lesions

\begin{tabular}{|c|c|c|}
\hline Sample\# & Diagnosis & E-Cadherin MSP* \\
\hline 4 & Nonneoplastic skin & Negative \\
\hline 14 & Nonneoplastic skin & Negative \\
\hline 6 & Nonneoplastic skin & Negative \\
\hline 25 & Nonneoplastic skin & Negative \\
\hline 8 & Nonneoplastic skin & Negative \\
\hline 29 & Nonneoplastic skin & Negative \\
\hline 16 & Nonneoplastic skin & Negative \\
\hline 3 & Nonneoplastic skin & Positive \\
\hline 30 & Nonneoplastic skin & Positive \\
\hline 15 & Actinic keratosis & Negative \\
\hline 7 & Actinic keratosis & Negative \\
\hline 28 & Actinic keratosis & Negative \\
\hline 26 & Actinic keratosis & Negative \\
\hline 22 & Actinic keratosis & Negative \\
\hline 33 & Actinic keratosis & Positive \\
\hline 32 & Actinic keratosis & Positive \\
\hline 18 & Actinic keratosis & Positive \\
\hline 11 & Actinic keratosis & Positive \\
\hline 10 & SCC $\S$ in situ & Negative \\
\hline 35 & SCC in situ & Negative \\
\hline 24 & SCC in situ & Negative \\
\hline 34 & SCC in situ & Negative \\
\hline 13 & SCC in situ & Positive \\
\hline 19 & SCC in situ & Positive \\
\hline 36 & SCC in situ & Positive \\
\hline 12 & SCC in situ & Positive \\
\hline 2 & Invasive SCC & Negative \\
\hline 9 & Invasive SCC & Positive \\
\hline 5 & Invasive SCC & Positive \\
\hline 1 & Invasive SCC & Positive \\
\hline 21 & Invasive SCC & Positive \\
\hline 17 & Invasive SCC & Positive \\
\hline 31 & Invasive SCC & Positive \\
\hline
\end{tabular}

* MSP; methylation-specific PCR

§ SCC; squamous cell carcinoma 
neoplastic skin control. Figure 1 shows representative methylation-specific PCR results obtained from five skin samples. Samples 5 (invasive squamous cell carcinoma), 19 (squamous cell carcinoma in situ), and 33 (actinic keratosis) show amplification of both unmethylated and methylated-specific amplicons, indicating the presence of E-cadherin promoter hypermethylation (Samples 5, 19, and 33 in Fig. 1). In Samples 10 (squamous cell carcinoma in situ) and 15 (actinic keratosis), only the amplification of unmethylated-specific amplicons is seen, indicative of a lack of E-cadherin promoter hypermethylation in these samples (Samples 10 and 15 in Fig. 1). Positive and negative controls worked appropriately in each round of PCR reaction.

The overall prevalence of E-cadherin promoter hypermethylation in dysplastic (actinic keratosis), carcinoma in situ, and invasive carcinoma is estimated at $14 / 24(58 \%)$, underlining that E-cadherin is a common target for epigenetic silencing in cutaneous squamous carcinogenesis.

\section{DISCUSSION}

Previous immunohistochemical studies have suggested that decreased or lost protein expression of the E-cadherin gene in primary skin squamous cell carcinomas is frequent (25-29) and is associated with high mitotic activity (29), poorer tumor differentiation $(27,28)$, and increased tendency for regional lymph node metastases (25). Similarly, decreased protein expression of the E-cadherin gene has been shown to correlate with advancing $\mathrm{T}$ and $\mathrm{N}$ stages of oral squamous cell carcinoma and a poor tumor cell differentiation (31). It has been well established that the E-cadherin gene is a tumor suppressor gene and is a prime target for epigenetic silencing in association with $\mathrm{CpG}$ island hypermethylation within the promoter region in a wide variety of human cancer (11-22).

A CpG island is a small DNA stretch (500 to 200 base pairs in length), located around or within the promoter region of many housekeeping genes, and typically consisting of $\geq 50 \%$ cytosine (C) and guanosine $(\mathrm{G})$ content with $\mathrm{CpG} / \mathrm{GpC}$ ratio of $\geq 1$ (32). The $\mathrm{CpG}$ island is normally free of methylation to permit normal gene function and is suppressive

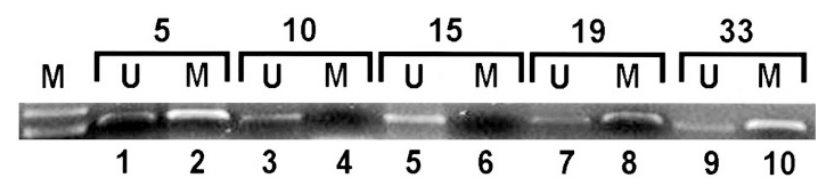

FIGURE 1. Bisulfite-modified DNA harvested from skin samples numbered as Samples 5 (Lanes 1-2), 10 (Lanes 3-4), 15 (Lanes 5-6), 19 (Lanes 7-8), and 33 (Lanes 9-10) was subjected to methylation-specific PCR using unmethylated (U) or methylated-specific (M) MSP primer sets for E-cadherin. for gene expression when methylated (32). The CpG islands are typically unmethylated in normal tissues but are methylated to varying degrees in many human cancer types $(33,34)$. The epigenetic silencing in association with promoter $\mathrm{CpG}$ island hypermethylation often cooperates with genetic changes (somatic mutation or allelic loss) in inactivating a number of tumor suppressor genes such as p16 ${ }^{\text {Ink } 4 a}$, E-cadherin, $p V H L$, and death associated protein kinase (35).

Promoter hypermethylation of one allele is often preceded by loss of the opposite allele $(8,9)$, simulating the type of loss of heterozygosity that is usually seen with loss of tumor suppressor function due to point mutation.

Because E-cadherin has been established as a prime target for epigenetic silencing in many human tumor types, we attempt to determine the prevalence of E-cadherin promoter hypermethylation in the continuum from nonneoplastic skin to actinic keratosis, squamous cell carcinoma in situ, and invasive squamous cell carcinoma. In the present study, we found that the overall frequency of E-cadherin promoter hypermethylation was very high $(14 / 24 ; 58 \%)$ in both preneoplastic (actinic keratosis) and malignant (carcinoma in situ and invasive carcinoma) cutaneous lesions.

The highest frequency of E-cadherin promoter hypermethylation was detected in invasive squamous cell carcinoma $(6 / 7 ; 85 \%)$, followed by that seen in squamous cell carcinoma in situ $(4 / 8 ; 50 \%)$ and in actinic keratosis (4/9; 44\%). Interestingly, promoter hypermethylation was also present in 2 of 9 (22\%) nonneoplastic skin controls (see Results and Table 1).

Our data clearly indicate that E-cadherin gene is a prime target for epigenetic silencing in ultraviolet-induced squamous carcinogenesis of the skin, as has been established in many other forms of human cancer (11-22) and that increased frequency of E-cadherin promoter hypermethylation appears to be associated with more advanced stages of squamous carcinogenesis of the skin.

Because we did not perform immunohistochemical studies on these 33 cases, we did not know the functional status of the E-cadherin gene in those 10 cases of dysplastic or malignant skin lesions (5 actinic keratosis, 4 carcinoma in situ, and 1 invasive carcinoma) that were negative for E-cadherin promoter hypermethylation (Table 1). In the future, studies should include both protein expression and promoter methylation analyses in a larger series of dysplastic or malignant skin lesions to further clarify the significance of E-cadherin promoter hypermethylation and the relationship between the epigenetic alterations of the E-cadherin gene and protein expression in cutaneous squamous carcinogenesis. 
It is noteworthy that two of nine cases of nonneoplastic skin control were also positive for E-cadherin promoter hypermethylation (see Results and Table 1). It is well recognized that E-cadherin promoter hypermethylation can be seen in normal nonneoplastic tissues, particularly in elderly individuals $(11,17)$. In a study by Bornman and his colleagues (17), E-cadherin promoter hypermethylation was present in 20 of 47 (43\%) cases of bladder cancer as well as in 3 of 9 (33\%) samples of histologically normal bladder tissues. All these three samples were from individuals older than 70 years of age. In another study on neoplastic and nonneoplastic gastric epithelia obtained at autopsy by Waki et al. (11), the investigators identified E-cadherin promoter hypermethylation in stomach cancer (44/ $94,47 \%)$, nonneoplastic gastric mucosa adjacent to the cancer $(63 / 94 ; 67 \%)$, normal gastric mucosa from healthy individuals aged $>45$ years (12/14; $86 \%$ ) but not in the normal gastric mucosa from healthy individuals aged $<22$ years $(0 / 6)$. It is hypothesized that E-cadherin promoter hypermethylation during aging may signal the beginning of gastric cancer in these older, but otherwise healthy individuals (11).

Two nonneoplastic skin controls positive for E-cadherin promoter hypermethylation were from patients of 50 and 43 years of age, respectively, in this study, and this finding may indicate the earliest stage of squamous carcinogenesis in these two individuals.

In summary, we have used a highly specific and sensitive methylation-specific PCR to determine the prevalence of promoter hypermethylation in the E-cadherin gene in a series of nonneoplastic, dysplastic, and malignant skin lesions. We found that E-cadherin promoter hypermethylation was frequent in dysplastic and malignant skin lesions $(14 / 24 ; 58 \%)$ and that the frequency is increased with more advanced diseases. We therefore conclude that the E-cadherin gene, as has been established in many other types of human cancer, is also a prime target for epigenetic silencing in primary squamous carcinoma of the skin.

\section{REFERENCES}

1. Takeichi M. Morphogenetic roles of classic cadherins. Curr Opin Cell Biol 1995;7:619-27.

2. Kremmidiotis G, Baker E, Crawford J, et al. Localization of human cadherin genes to chromosome regions exhibiting cancer-related loss of heterozygosity. Genomics 1998;49:467-71.

3. Girard L, Zochbauer-Muller S, Virmani AK, et al. Genomewide allelotyping of lung cancer identifies new regions of allelic loss, differences between small cell lung cancer and non-small cell lung cancer, and loci clustering. Cancer Res 2000;60:4894-906.
4. Behrens J. Cadherins and catenins: role in signal transduction and tumor progression. Cancer Metastasis Rev 1999;18: 15-30.

5. Ohene-Abuakwa Y, Pignatelli MAmicb. Adhesion molecules in cancer biology. Adv Exp Med Biol 2000;465:115-26.

6. Takeichi M. Cadherin cell adhesion receptors as a morphogenetic regulator. Science 1991;251:1451-5.

7. Knudson AGJ. Hereditary cancer, oncogene, and antioncogenes. Cancer Res 1985;45:1437-43.

8. Merlo A, Herman JG, Mao L, et al. 5'-CpG island methylation is associated with transcriptional silencing of the tumor suppressor p16/CDKN2/MTS1 in human cancers. Nat Med 1995;1:686-92.

9. Herman JG, Latif F, Weng Y, et al. Silencing of the VHL tumor-suppressor gene by DNA methylation in renal carcinoma. Proc Natl Acad Sci U S A 1994;91:9700-4.

10. Baylin SB, Herman JG, Graff JR, et al. Alterations in DNA methylation: a fundamental aspect of neoplasia. In: Klein G, Van de Woude GF, editors. Advances in cancer research. San Diego, CA: Academic Press; 1998. p. 141-96.

11. Waki T, Tamura G, Tsuchiya T, et al. Promoter methylation status of E-cadherin, hMLH1, and p16 genes in nonneoplastic gastric epithelia. Am J Pathol 2002;161:399-403.

12. Kang GH, Lee S, Kim JS, et al. Profile of aberrant CpG island methylation along multistep gastric carcinogenesis. Lab Invest 2003;83:519-26.

13. Woodson K, Hayes R, Wideroff L, et al. Hypermethylation of GSTP1, CD44, and E-cadherin genes in prostate cancer among US blacks and whites. Prostate 2003;55:199-205.

14. Chen CL, Liu SS, Lp SM, et al. E-cadherin expression is silenced by DNA methylation in cervical cancer cell lines and tumours. Eur J Cancer 2002;39:517-23.

15. Garinis GA, Menounos PG, Spanakis NE, et al. Hypermethylation-associated transcriptional silencing of E-cadherin in primary sporadic colorectal carcinomas. J Pathol 2002;198:442-9.

16. Horikawa Y, Sugano K, Shigyo M, et al. Hypermethylation of an E-cadherin $(\mathrm{CDH} 1)$ promoter region in high grade transitional cell carcinoma of the bladder comprising carcinoma in situ. J Urol 2003;169:1541-5.

17. Bornman DM, Mathew S, Alsruhe J, et al. Methylation of the E-cadherin gene in bladder neoplasia and in normal urothelial epithelium from elderly individuals. Am J Pathol 2001; 159:831-5.

18. Toyooka KO, Toyooka S, Maitra A, et al. Establishment and validation of real-time polymerase chain reaction method for CDH1 promoter methylation. Am J Pathol 2002;162:62934.

19. Si HX, Tsao SW, Lam KY, et al. E-cadherin expression is commonly downregulated by $\mathrm{CpG}$ island hypermethylation in esophageal carcinoma cells. Cancer Lett 2001;173:71-8.

20. Yeh KT, Shih MC, Lin TH, et al. The correlation between CpG methylation on promoter and protein expression of E-cadherin in oral squamous cell carcinoma. Anticancer Res 2002;22:3971-5.

21. Tsao SW, Liu Y, Wang X, et al. The association of E-cadherin expression and the methylation status of the E-cadherin gene in nasopharyngeal carcinoma cells. Eur J Cancer 2002; 39:524-31.

22. Viswanathan M, Tsuchida N, Shanmugam G. Promoter hypermethylation profile of tumor-associated genes p16, p15, hMLH1, MGMT and E-cadherin in oral squamous cell carcinoma. Int J Cancer 2003;105:41-6.

23. Pizarro A, Benito N, Navarro P, et al. E-cadherin expression in basal cell carcinoma. Br J Cancer 1994;69:157-62.

24. Fuller LC, Allen MH, Montesu M, et al. Expression of E-cadherin in human epidermal non-melanoma cutaneous tumours. Br J Dermatol 1996;134:28-32. 
25. Koseki S, Aoki T, Ansai S, et al. An immunohistochemical study of E-cadherin expression in human squamous cell carcinoma of the skin: relationship between decreased expression of E-cadherin in the primary lesion and regional lymph node metastasis. J Dermatol 1999;26: $416-22$.

26. Koseki S, Ansai S, Aoki T, et al. E-cadherin expression in skin tumors using an AMeX immunohistostaining method. J Dermatol 2000;27:307-11.

27. $\mathrm{Wu} \mathrm{H}$, Lotan R, Menter D, et al. Expression of E-cadherin is associated with squamous differentiation in squamous cell carcinomas. Anticancer Res 2000;20:1385-90.

28. Bayer-Garner IB, Smoller BR. The expression of syndecan-1 is preferentially reduced compared with that of E-cadherin in acantholytic squamous cell carcinoma. J Cutan Pathol 2001;28:83-9.

29. Papadavid E, Pignatelli M, Zakynthinos S, et al. Abnormal immunoreactivity of the E-cadherin/catenin (alpha-, beta-, and gamma-) complex in premalignant and malignant nonmelanocytic skin tumours. J Pathol 2002;196:154-62.

30. Lee TL, Leung WK, Chan MWY, et al. Detection of gene promoter hypermethylation in the tumor and serum of patients with gastric carcinoma. Clin Cancer Res 2002;8:1761-6.

31. Yamada K, Jordan R, Mori M, et al. The relationship between E-cadherin expression, clinical stage and tumour differentiation in oral squamous cell carcinoma. Oral Dis 1997;3:82-5.

32. Bird AP. CpG-rich islands and the function of DNA methylation. Nature 1986;321:209-13.

33. Jones PA. DNA methylation errors and cancer. Cancer Res 1996;56:2463-7.

34. Jones PA, Laird PW. Cancer epigenetics come of age. Nat Genet 1999;15:163-7.

35. Herman JG, Baylin SB. Promoter-region hypermethylation and gene silencing in human cancer. In: Jones PA, Vogt PK, Compans RW, et al., editors. DNA methylation and cancer. 1st ed. New York: Springer-Verlag; 2000. p. 35-50. 